\title{
Water isotopic ratios from a continuously melted ice core sample
}

\author{
V. Gkinis ${ }^{1}$, T. J. Popp ${ }^{1}$, T. Blunier ${ }^{1}$, M. Bigler ${ }^{2}$, S. Schüpbach ${ }^{2}$, E. Kettner ${ }^{1}$, and S. J. Johnsen ${ }^{1,3}$ \\ ${ }^{1}$ Centre for Ice and Climate, Niels Bohr Institute, University of Copenhagen, Juliane Maries Vej 30, \\ 2100 Copenhagen, Denmark \\ ${ }^{2}$ Physics Institute, Climate and Environmental Physics and Oeschger Centre for Climate Change Research University of Bern, \\ Sidlerstrasse 5, 3012 Bern, Switzerland \\ ${ }^{3}$ Science Institute, University of Iceland, Dunhaga 3, 107, Iceland
}

Received: 13 May 2011 - Published in Atmos. Meas. Tech. Discuss.: 27 June 2011

Revised: 3 November 2011 - Accepted: 11 November 2011 - Published: 24 November 2011

\begin{abstract}
A new technique for on-line high resolution isotopic analysis of liquid water, tailored for ice core studies is presented. We built an interface between a Wavelength Scanned Cavity Ring Down Spectrometer (WS-CRDS) purchased from Picarro Inc. and a Continuous Flow Analysis (CFA) system. The system offers the possibility to perform simultaneuous water isotopic analysis of $\delta^{18} \mathrm{O}$ and $\delta \mathrm{D}$ on a continuous stream of liquid water as generated from a continuously melted ice rod. Injection of sub $\mu \mathrm{l}$ amounts of liquid water is achieved by pumping sample through a fused silica capillary and instantaneously vaporizing it with $100 \%$ efficiency in a home made oven at a temperature of $170^{\circ} \mathrm{C}$. A calibration procedure allows for proper reporting of the data on the VSMOW-SLAP scale. We apply the necessary corrections based on the assessed performance of the system regarding instrumental drifts and dependance on the water concentration in the optical cavity. The melt rates are monitored in order to assign a depth scale to the measured isotopic profiles. Application of spectral methods yields the combined uncertainty of the system at below $0.1 \%$ and $0.5 \%$ for $\delta^{18} \mathrm{O}$ and $\delta \mathrm{D}$, respectively. This performance is comparable to that achieved with mass spectrometry. Dispersion of the sample in the transfer lines limits the temporal resolution of the technique. In this work we investigate and assess these dispersion effects. By using an optimal filtering method we show how the measured profiles can be corrected for the smoothing effects resulting from the sample dispersion. Considering the significant advantages the technique
\end{abstract}

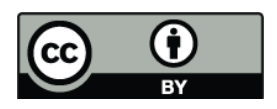

Correspondence to: V. Gkinis (v.gkinis@nbi.ku.dk) offers, i.e. simultaneuous measurement of $\delta^{18} \mathrm{O}$ and $\delta \mathrm{D}$, potentially in combination with chemical components that are traditionally measured on CFA systems, notable reduction on analysis time and power consumption, we consider it as an alternative to traditional isotope ratio mass spectrometry with the possibility to be deployed for field ice core studies. We present data acquired in the field during the 2010 season as part of the NEEM deep ice core drilling project in North Greenland.

\section{Introduction}

Polar ice core records provide some of the most detailed views of past environmental changes up to $800000 \mathrm{yr}$ before present, in large part via proxy data such as the water isotopic composition and embedded chemical impurities. One of the most important features of ice cores as climate archives, is their continuity and the potential for high temporal resolution. Greenland ice cores are particularly well suited for high resolution paleoclimatic studies, because relatively high snow accumulation rates allow seasonal changes in proxy data to be identified more than $50000 \mathrm{yr}$ in the past (Johnsen et al., 1992; NGRIP members, 2004).

The isotopic signature of polar precipitation, commonly expressed through the $\delta$ notation $^{1}$ (Epstein, 1953; Mook,

\footnotetext{
${ }^{1}$ Isotopic abundances are typically reported as deviations of a sample's isotopic ratio relative to that of a reference water (e.g. VSMOW) expressed in per mil (\%o) through the $\delta$ notation: $\delta^{i}=$ $\left(\frac{{ }^{i} R_{\text {sample }}}{{ }^{i} R_{\text {SMOW }}}-1\right) \times 1000$ where ${ }^{2} R=\frac{{ }^{2} \mathrm{H}}{{ }^{1} \mathrm{H}}$ and ${ }^{18} R=\frac{{ }^{18} \mathrm{O}}{{ }^{16} \mathrm{O}}$
} 
2000) is related to the temperature gradient between the evaporation and condensation site (Dansgaard, 1964) and has so far been used as a proxy for the temperature of the cloud at the time of condensation (Jouzel and Merlivat, 1984; Jouzel et al., 1997; Johnsen et al., 2001). One step further, the combined signal of $\delta \mathrm{D}$ and $\delta^{18} \mathrm{O}$ commonly referred to as the deuterium excess (hereafter $\mathrm{D}_{\mathrm{xs}}$ ), constitutes a useful paleothermometer tool. Via its high correlation with the temperature of the evaporation source (Johnsen et al., 1989), it has been used to resolve issues related to changes in the location of the evaporation site (Cuffey and Vimeux, 2001; Kavanaugh and Cuffey, 2002). A relatively recent advance in the use of water isotope ratios as a direct proxy of firn temperatures, has been introduced by Johnsen et al. (2000). Assessment of the diffusivity of the water isotopologues in the porous medium of the firn column can yield a temperature history, provided a dating model is available.

The measurement of water stable isotopic composition is typically performed off-line via discrete sampling with traditional isotope ratio mass spectrometry (hereafter IRMS). While high precision and accuracy can routinely be achieved with IRMS systems, water isotope analysis remains an elaborate process, which is demanding in terms of sample preparation, power consumption, sample size, consumables, isotope standards and carrier gases. The analysis of a deep ice core at its full length in high resolution (typically 2.5 to $5 \mathrm{~cm}$ per sample) requires the processing of a vast amount of water samples and can take years to complete. Additionally, these procedures often come at the expense of not fully exploiting the temporal resolution available in the ice core.

Laser spectroscopy in the near and mid infrared region has been demonstrated as a potential alternative for water isotope analysis, presenting numerous advantages over IRMS (Kerstel et al., 1999; Kerstel, 2004). A major advantage of the technique is the ability to directly inject the sampled water vapour in the optical cavity of the spectrometer where both isotopic ratios ${ }^{18} \mathrm{O} /{ }^{16} \mathrm{O}$ and ${ }^{2} \mathrm{H} /{ }^{1} \mathrm{H}$ are measured simultaneuously. In contrast, in the most common IRMS techniques water is not measured as such, but has to be converted to a different gas prior to measurement. For $\delta^{18} \mathrm{O}$ analysis, the $\mathrm{CO}_{2}$ equilibration method (Epstein, 1953) has been widely used, whereas $\delta \mathrm{D}$ analysis commonly involves the reduction of water to hydrogen gas over hot uranium (Bigeleisen et al., 1952; Vaughn et al., 1998; Huber and Leuenberger, 2003), or chromium (Ghere et al., 1996). However, the combined use of these two methods rules out simultaneous analysis of both water isotopologues on a given sample. More recently, in combination with the use of continuous flow mass spectrometers, conversion of water to $\mathrm{CO}$ and $\mathrm{H}_{2}$ is performed in a pyrolysis furnice (Begley and Scrimgeour, 1997) and allows simultaneous $\delta \mathrm{D}$ and $\delta^{18} \mathrm{O}$ measurement, but still on a single discrete sample. One of the drawbacks of this technique is the interference of $\mathrm{NO}$, formed at the ion source by the reaction of $\mathrm{N}_{2}$ and $\mathrm{O}_{2}$ with the $\mathrm{CO}$ signal at $\mathrm{m} / z=30$ (Accoe, 2008). Nowadays, commercial IR spectrometers are available with a precision comparable to IRMS systems (Lis et al., 2008; Brand et al., 2009). These units typically receive a continuous stream of water vapor and offer ease of use and portability.

The analysis of another set of ice core proxies, that of chemical impurities, has similarly been an elaborate process, traditionally performed with liquid chromatography techniques. With the advent of Continuous Flow Analysis (heareafter CFA) from continuously melted ice core segments, the measurement of chemical impurities has reached the point of largely exploiting the high resolution available in the core while it is often performed in the field (Sigg et al., 1994; Röthlisberger et al., 2000; Kaufmann et al., 2008). The continuous, on-line nature of the technique has resulted in a considerable reduction in sample preparation and processing times. Recently, Schüpbach et al. (2009) demonstrated the measurement of $\mathrm{CH}_{4}$ mixing ratios in an on-line semi continuous mode with the use of a gas chromatograph combined with a pulsed discharge and a thermal conductivity detector.

Here, we demonstrate the ability to perform continuous measurements of water isotope ratios from a stream of water vapor derived from a continuously melting ice rod by coupling a commercial IR spectrometer to a CFA system via a passive, low volume flash evaporation module. In the following, we assess the system's precision, accuracy, and efficient calibration. We then comment on issues related to sample dispersion in the sample transfer lines, the evaporation module and the optical cavity of the spectrometer itself in order to determine the expected smoothing imposed on the acquired data sets. Finally, isotopic analysis of ice core samples from the NEEM deep ice core are presented and compared to measurements performed in discrete mode.

\section{Experimental}

\subsection{Continuous flow analysis}

In the system described here, (Fig. 1) an ice rod measuring $3.2 \times 3.2 \times 110 \mathrm{~cm}$ (hereafter CFA run) is continuously melted on a copper, gold-nickel coated melter at a regulated temperature of $20^{\circ} \mathrm{C}$. The concentric arrangement of the melter's surface facilitates the separation of the sample that originates from the outer and inner part of the core. Approximately $90 \%$ of the sample from the inner part is transfered to the analytical system by means of a peristaltic pump with a flow rate of $16 \mathrm{ml} \mathrm{min}{ }^{-1}$. This configuration provides an overflow of $\approx 10 \%$ from the inner to the outer part of the melter and ensures that the water sample that is introduced into the analytical system is not contaminated.

A stainless steel weight sitting on top of the ice rod enhances the stability and continuity of the melting process. An optical encoder connected to the stainless steel weight, records the displacement of the rod. This information is used 


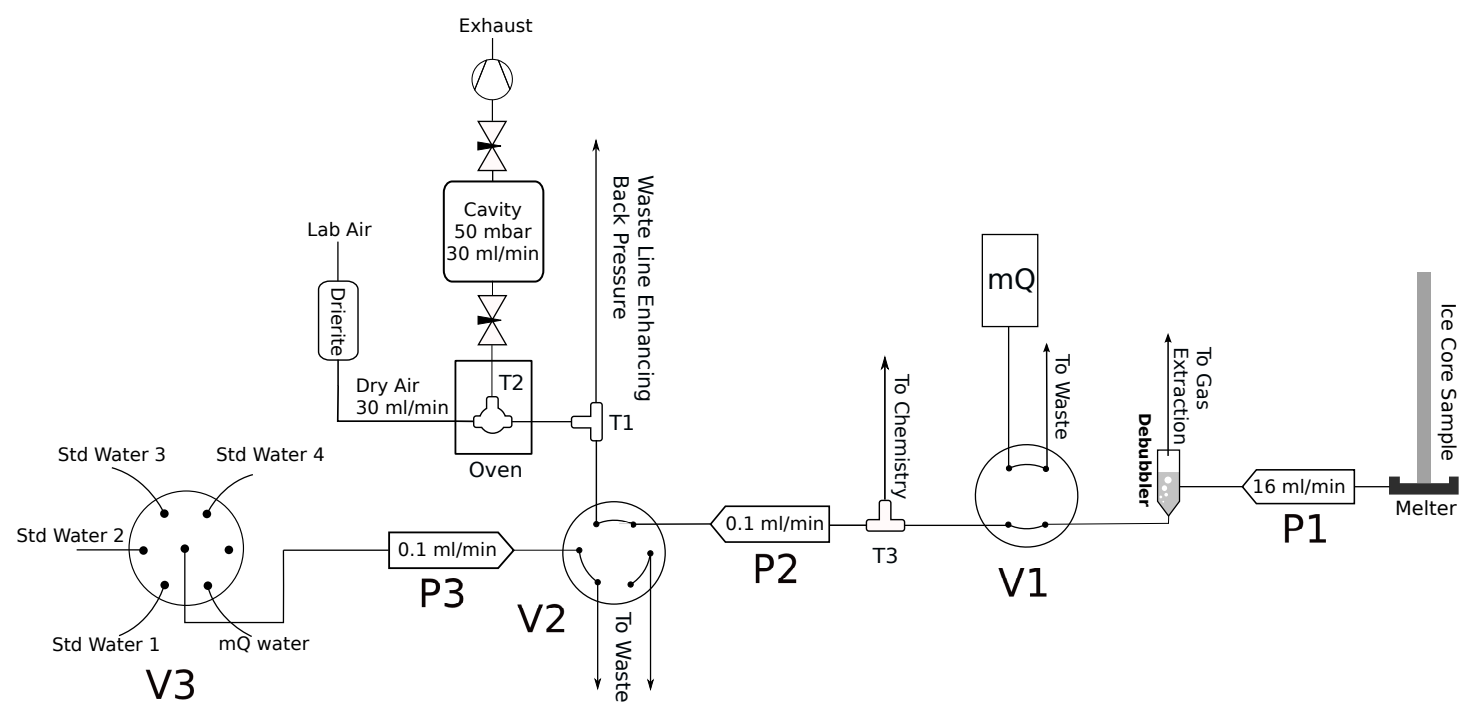

Fig. 1. Block diagram of the CFA-CRDS system.

to accurately define the depth scale of the produced water isotope data. Breaks in the ice rod are logged prior to the melting process and accounted for, during the data analysis procedure.

Gases included in the water stream originating from the air bubbles in the ice core are extracted in a sealed debubbler, with a volume of $\approx 300 \mu$ l. The melt rate of the present system is approximately $3.2 \mathrm{~cm} \mathrm{~min}^{-1}$, thus resulting in an analysis time of $\approx 35 \mathrm{~min}$ per CFA run. During the intervals between CFA runs, $\mathrm{mQ}^{2}$ water is pumped through the system. A 4-port injection valve (V1 in Fig. 1) allows the selection between the mQ and sample water. The $\mathrm{mQ}$ water is spiked with isotopically enriched water containing 99.8 atom \% deuterium, Cortecnet Inc.) in a mixing ratio of $\approx 1 \mathrm{ppm}$. In this way a distinction between sample and $\mathrm{mQ}$ water is possible, facilitating the identification of the beginning and end times of a CFA run.

For further details on the analysis of chemical components or the extraction of gases for greenhouse gas measurements the reader is refered to Kaufmann et al. (2008) and Schüpbach et al. (2009).

\subsection{The water isotope measurement}

We follow the same approach as previously presented in Gkinis et al. (2010) by coupling a commercially available Cavity Ring Down IR spectrometer (hereafter WS-CRDS) purchasecd from Picarro Inc. (Picarro L1102-i) (Crosson, 2008). The spectrometer operates with a gas flow rate of 30 standard $\mathrm{ml} \mathrm{min}^{-1}$. In the optical cavity the pressure is regulated at 47 mbar with two proportional valves in a feedback loop configuration up- and down-stream of the optical

\footnotetext{
${ }^{2}$ filtered and deionized water with a resistivity more than $18.2 \mathrm{M} \Omega \mathrm{cm}$ and a total organic content less than $10 \mathrm{ppb}$.
}

cavity at a temperature of $80^{\circ} \mathrm{C}$. The high signal to noise ratio achieved with the Cavity Ring Down configuration in combination with fine control of the environmental parameters of the spectrometer, result in a performance comperable to modern mass spectrometry systems taylored for water stable isotope analysis.

A 6-port injection valve (V2 in Fig. 1) selects sample from the CFA line or a set of local water standards. The isotopic composition of the local water standards is determined with conventional IRMS and reported with respect to VSMOW standard. A 6-port selection valve (V3 in Fig. 1) is used for the switch between different water standards. A peristaltic pump (P3 in Fig. 1) in this line with variable speeds, allows adjustment of the water vapor concentration in the spectrometer's optical cavity, by varying the pump speed. In that way, the system's sensitivity to levels of different water concentration can be investigated and a calibration procedure can be implemented. We use high purity Perfluoroalkoxy (PFA) tubing for all sample transfer lines.

Injection of water sample into the evaporation oven takes place via a $\varnothing 40 \mu \mathrm{m}$ fused silica capillary where immediate and $100 \%$ evaporation takes place avoiding any fractionation effects. The setpoint of the evaporation temperature is set to $170^{\circ} \mathrm{C}$ and is regulated with a PID controller. The amount of the injected water to the oven can be adjusted by the pressure gradient maintained between the inlet and waste ports of the T1 tee-split (Fig. 1). The latter depends on the ratio of the inner diameters of the tubes connected to the two ports as well as the length of the waste line. The total water sample consumption is $\approx 0.1 \mathrm{ml} \mathrm{min}^{-1}$ maintained by the peristaltic pump P2 (Fig. 1). For a detailed description of the sample preparation and evaporation module the reader may reffer to Gkinis et al. (2010). A smooth and undisturbed sample delivery to the spectrometer at the level of $\approx 20000 \mathrm{ppm}$ results 

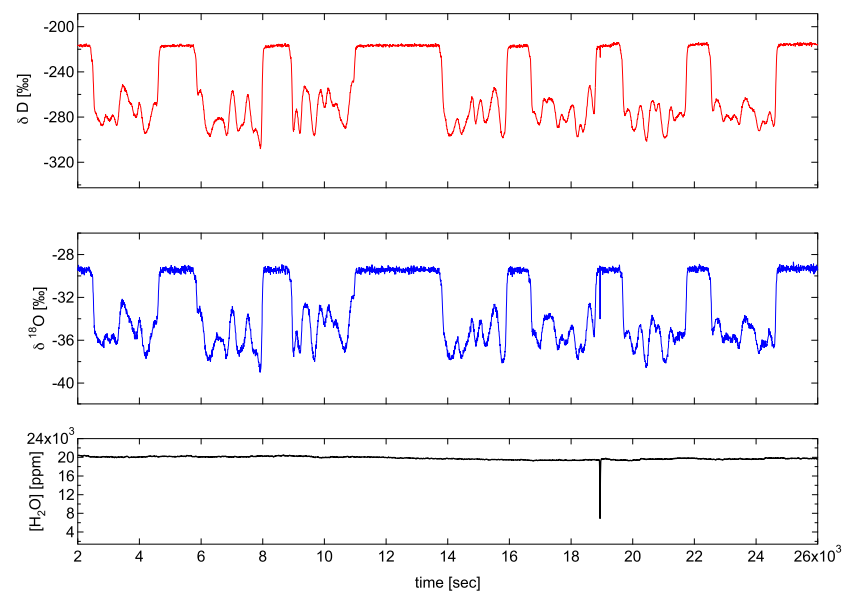

Fig. 2. Raw signals spanning 7 CFA runs on 29 May 2010.

in optimum performance of the system. Fluctuations of the sample flow caused by air bubbles or impurities are likely to result in a deteriorated performance of the measurement and are occasionally observed as extreme outliers on both $\delta^{18} \mathrm{O}$ and $\delta \mathrm{D}$ measurements. The processes that control the occurence of these events are still not well understood.

\section{Results and discussion - from raw data to isotope records}

In this study we present data collected in the framework of the NEEM ice core drilling project. Measurements were carried out in the field during the 2010 field season and span $919.05 \mathrm{~m}$ of ice core (depth interval 1281.5-2200.55 m). Here we exemplify the performance of the system over a section of ice from the depth interval 1382.152-1398.607. The age of this section spans $\approx 411$ yr with a mean age of $10.9 \mathrm{kab}_{2} \mathrm{k}^{3}$. The reported age is based on a preliminary time scale constructed by stratigraphic transfer of the GICC05 time scale (Rasmussen et al., 2006) from the NGRIP to the NEEM ice core.

In Fig. 2 we present an example of raw data as acquired by the system. This data set covers 7 CFA runs $(7.70 \mathrm{~m}$ of ice). A clear baseline of the isotopically heavier $\mathrm{mQ}$ water can be seen in between CFA runs. At $t=1.9 \times 10^{4} \mathrm{~s}$ one can observe a sudden drop in the signal of the water concentration due to a scheduled change of the $\mathrm{mQ}$ water tank. Adjacent to this, both $\delta^{18} \mathrm{O}$ and $\delta \mathrm{D}$ signals present a clear spike, characteristic of the sensitivity of the system to the stability of the sample flow rates.

\subsection{VSMOW - water concentration calibrations}

Before any further processing we correct the acquired data for fluctuations of the water concentration in the optical

\footnotetext{
${ }^{3}$ thousand years before $2000 \mathrm{AD}(\mathrm{ka} \mathrm{b} 2 \mathrm{k})$
}

cavity. To a good approximation the $\delta^{18} \mathrm{O}$ and $\delta \mathrm{D}$ signals show a linear response to differences in water concentrations around 20000 ppmv (Brand et al., 2009; Gkinis et al., 2010). A correction is performed as:

$\Delta \delta=\alpha\left(R_{20}-1\right)$

Here $R_{20}=\frac{\left[\mathrm{H}_{2} \mathrm{O}\right]}{20000}, \alpha_{18}=1.94 \% \circ$ and $\alpha_{\mathrm{D}}=3.77 \%$ as estimated in Gkinis et al. (2010). The estimation of these values has been performed several times during the period July 2009-October 2011. Based on compiled data from 6 calibrations we can report that these values do not appear to be drifting in the course of the two years. The values reported here are the ones estimated chronologically closer to the measurements we present here. These values are most likely instrument specific and should be used with caution for other analyzers. We typically operate the system in the area of 17 000-22 000 ppmv in which we observe no impact of the water concentration level on the precision of the isotopic signal. The mean and standard deviation of the water concentration signal in the course of aprroximately $7 \mathrm{~h}$ as seen in Fig. 2 is $19939 \pm 306$ ppmv. The water concentration correction is applied to the raw data, scaling all the isotopic values to the level of $20000 \mathrm{ppmv}$.

Raw data are expressed in per mil values for both $\delta^{18} \mathrm{O}$ and $\delta \mathrm{D}$ and ppmv for the water vapour concentration. These values are based on the slope and intercept values of the instrument's stored internal calibration line. Due to apparent instrumental drifts though, the latter are expected to deviate with time. To overcome this problem we perform frequent VSMOW calibrations by using 3 local water standards with well known $\delta^{18} \mathrm{O}$ and $\delta \mathrm{D}$ values measured by conventional Isotope Ratio Mass Spectrometry combined with a pyrolysis glassy carbon reactor (Thermo DeltaV-TC/EA). The water standards are transported and stored in the field using the necessary precautions to avoid evaporation. We used amber glass bottles with silicon sealed caps. Two of the water standards are used to calculate the slope and the intercept of the calibration line and the third is used for a check of the linearity and the accuracy. The frequency of the VSMOW calibrations depends on the work flow of the overall CFA system. For the particular section we present here a VSMOW calibration was performed the same day.

In Fig. 3 we illustrate this calibration. Based on the measured and real values of the standards " -22 " and " -40 " the measurement of the "NEEM" standard can be used as a test for accuracy and linearity. In Table 1 we present the VSMOW calibrated values of the water standards as estimated with the IRMS system. The slope and intercept of the calibration lines are $[1.002,-0.007]$ for $\delta^{18} \mathrm{O}$ and [0.963, $-8.214]$ for $\delta \mathrm{D}$. Based on these values one can calculate the isotopic composition of the "NEEM" standard. The results we obtain are $-33.4 \%$ and $-256.99 \%$ for $\delta^{18} \mathrm{O}$ and $\delta \mathrm{D}$ respectively. This results in a difference of $0.04 \%$ o $(0.31 \%$ o $)$ for $\delta^{18} \mathrm{O}(\delta \mathrm{D})$, giving an indication about the accuracy obtained by the system. 

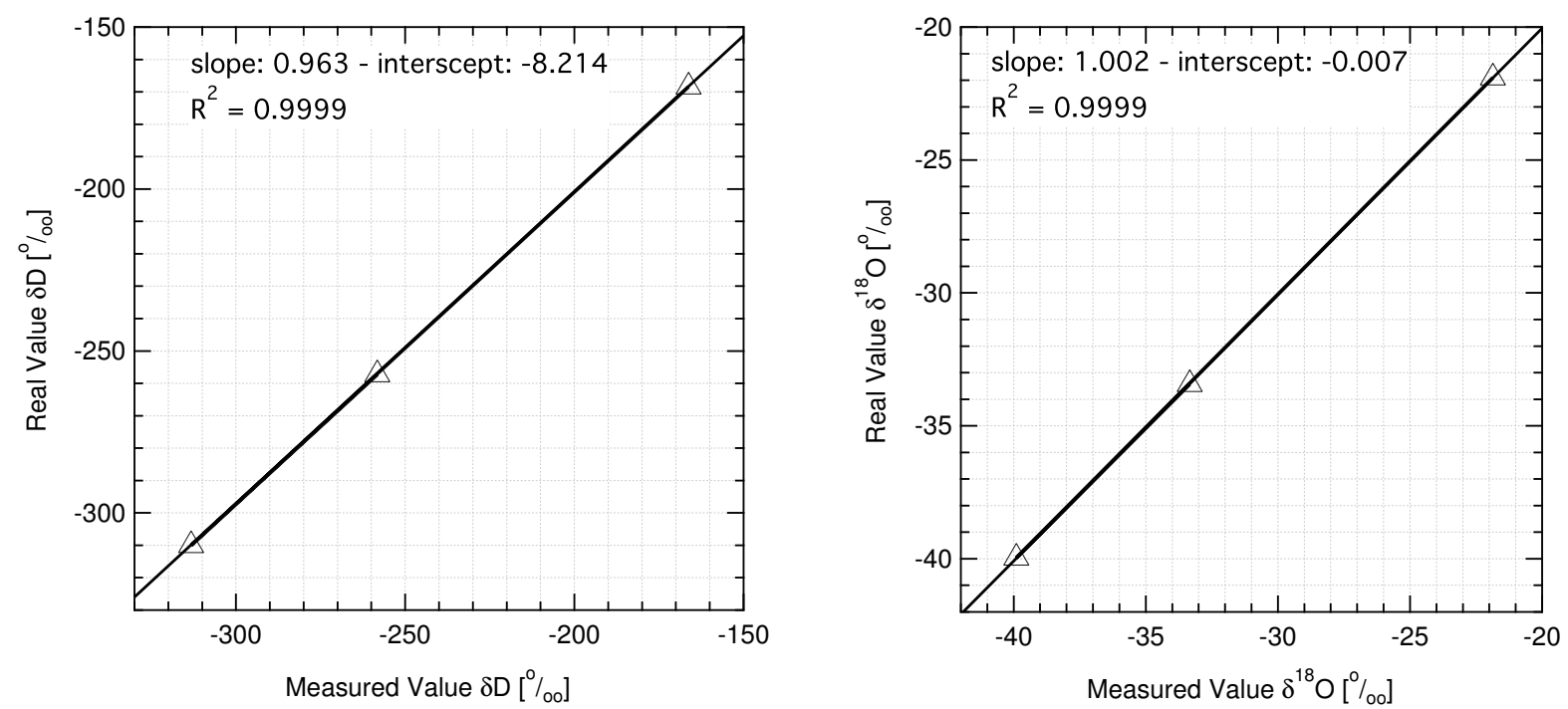

Fig. 3. VSMOW calibrations with three water standards " -22 ", " -40 " and "NEEM"; Left $-\delta \mathrm{D}$, right $-\delta^{18} \mathrm{O}$.

Table 1. Isotopic composition of the standards used for the VSMOW calibrations in \%o.

\begin{tabular}{rrrr}
\hline & -22 & NEEM & -40 \\
\hline$\delta^{18} \mathrm{O}$ & -21.9 & -33.44 & -39.97 \\
$\delta \mathrm{D}$ & -168.4 & -257.3 & -310 \\
\hline
\end{tabular}

\subsection{The depth scale}

The melting process is recorded by an optical encoder connected to the top of the stainless steel weight that lies on top of the ice rod. The data acquired by the optical encoder allow for a conversion of the measurement time scale to a depth scale. In order to locate the beginning and end of every run we take advantage of the isotopic step observed during the transition between $\mathrm{mQ}$ baseline and sample water. A smoothed version of the discrete derivative of the acquired isotope data for both $\delta^{18} \mathrm{O}$ and $\delta \mathrm{D}$ reveals a local minimum (maximum) for the beginning (end) of the measurement (Fig. 4). The logged depth of the top and the bottom of the CFA run is assigned to these points. Data that lie in the transition interval between $\mathrm{mQ}$ and sample water are manually removed from the series. Additional breaks within a CFA run that can possibly be created during the drilling or processing phase of the ice core, are taken into account at the last stage of the data analysis. If necessary and depending on their size, the gaps can be filled by means of some interpolation technique. Here, due to the small size of the gaps we use a linear interpolation scheme. The use of more advanced methods is also possible but is out of the scope of this work. The processed profiles presented in Fig. 4 are reported with a nominal resolution of $5 \mathrm{~mm}$. The interpolated sections are highlighted with gray bars. Their width indicates the length of the gaps.

\subsection{Noise level - comparison with discrete data}

An estimate of the noise level of the measurements can be obtained from the appropriately normalized power spectral density of the time series. Using the $\delta^{18} \mathrm{O}$ and $\delta \mathrm{D}$ data of the section under consideration, we implement an autoregressive spectral estimation method developed by Burg (1975) by the use of the algorithm introduced by Andersen (1974). The order of the autoregressive model is $M=300$. The standard deviation of the time series will be defined as:

$\sigma^{2}=\int_{-f_{c}}^{f_{c}}|\hat{\eta}(f)|^{2} d f$

where the Nyquist frequency is $f_{c}=100$ cycles $^{-1}$ and $|\hat{\eta}(f)|^{2}$ can be obtained by a linear fit on the flat high frequency part of the spectrum (Fig. 5). By performing this analysis we obtain $\sigma_{18}=0.055 \%$ ond $\sigma_{\mathrm{D}}=0.21 \%$.

In order to validate the quality of the calibrations as well as the estimated depth scale we compare the CFA data with measurements performed in a discrete fashion using the same WS-CRDS spectrometer in combination with a sample preparation evaporator system (Gupta et al., 2009) and an autosampler. The discrete samples are cut in a resolution of $5 \mathrm{~cm}$. The sample injection sequence takes into account apparent memory effects and results are reported on the VSMOW scale by appropriate calibration using local water standards. The results are illustrated in Fig. 6 for $\delta^{18} \mathrm{O}$ and $\delta \mathrm{D}$. The comparison of the data sets demonstrates validity of the 

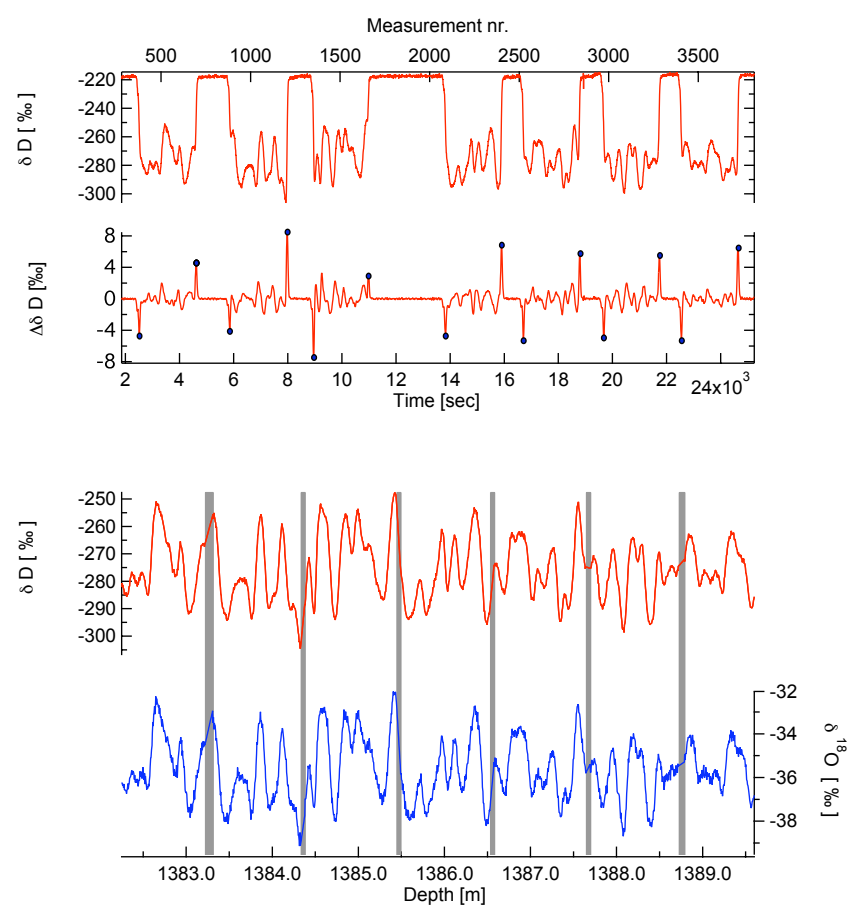

Fig. 4. The beginning and end of each CFA run is determined by the extrema of the 1st derivative of the isotopic signal, presented on the top graph. With gray bars we indicate the position and width of sections with data that are missing due to breaks in the ice, or removed in order to account for the transition from $\mathrm{mQ}$ water to sample and vice cersa.

followed calibration procedures. The benefits of the technique in terms of achieved resolution can be seen when one compares the two datasets over isotopic cycles with relatively small amplitude and higher frequency. Such an example can be seen at the depth of $1390.5 \mathrm{~m}$ where a sequence of 4 cycles is sampled relatively poorly with the discrete method when compared to the on-line system. This performance can benefit studies that look into the spectral properties of the signals by providing better statistics for the obtained measurements.

\subsection{Obtained resolution - diffusive sample mixing}

One of the advantages of the combined CFA-CRDS technique for water isotopic analysis of ice cores lies in the potential for higher resolution measurements relative to discrete sampling. However, diffusion effects in both the liquid and the vapor phase are expected to attenuate the obtained resolution.

Attenuation of the initial signal of the precipitation occurs also via a combination of in situ processes that take place after deposition. The porous medium of the firn column allows for an exchange of water molecules in the gas phase along the isotopic gradients of the profile. For the case of polar sites, this process has been studied extensively (Johnsen,

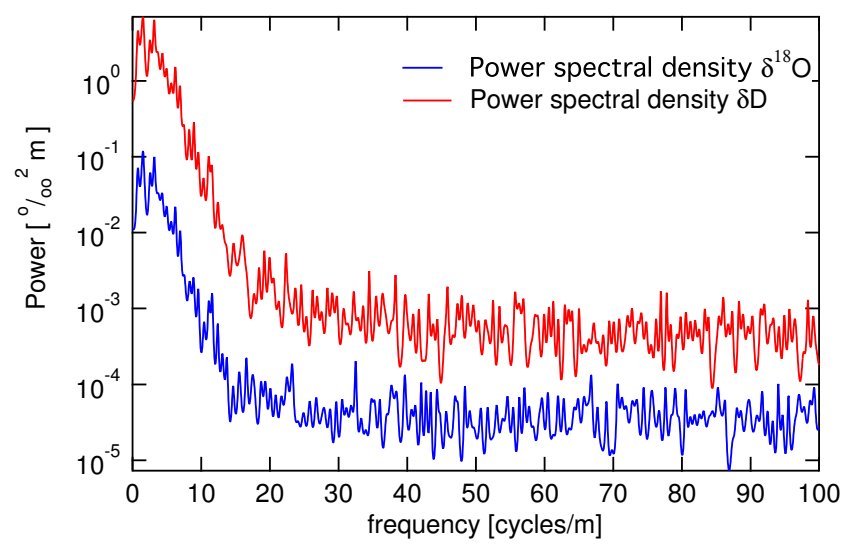

Fig. 5. $\delta^{18} \mathrm{O}$ and $\delta \mathrm{D}$ power spectral density based on the data of the interval $1382.152-1398.607 \mathrm{~m}$.

1977; Whillans and Grootes, 1985) and can be well described and quantified provided that a good estimate of the diffusivity coefficient and a strain rate history of the ice core site are available (Johnsen et al., 2000). The process ceases when the porous medium is closed-off and the diffusivity of air reaches zero at a density of $\approx 804 \mathrm{~kg} \mathrm{~m}^{-3}$. Deeper in the ice, diffusion within the ice crystals takes place via a process that is considerably slower when compared with the firn diffusion. At a temperature of $-30^{\circ} \mathrm{C}$ the diffusivity coefficients of these two processes differ by 4 orders of magnitude (Johnsen et al., 2000).

Assuming an isotopic signal $\delta_{\mathrm{pr}}$ for the precipitation, the total effect of the diffusive processes, in-situ and experimental, can be seen as the convolution of $\delta_{\mathrm{pr}}(z)$ with a smoothing filter $\mathcal{G}_{\text {tot }}$.

$\delta_{\mathrm{m}}(z)=\int_{-\infty}^{\infty} \delta_{\mathrm{pr}}(\tau) \mathcal{G}_{\mathrm{tot}}(z-\tau) d \tau=\left[\delta_{\mathrm{pr}} * \mathcal{G}_{\mathrm{tot}}\right](z)$

where $\delta_{\mathrm{m}}(z)$ is the measured signal and $(*)$ denotes the convolution operation. Since instrumental and in-situ firn-ice diffusion are statistically independent, the variance of the total smoothing filter is the sum of the variances of the in-situ and experimental smoothing filters (hereafter $\mathcal{G}_{\text {firn }}, \sigma_{\text {firn }}, \mathcal{G}_{\text {cfa }}$, $\left.\sigma_{\text {cfa }}\right)$.

$\sigma_{\text {tot }}^{2}=\sigma_{\text {firn }}^{2}+\sigma_{\text {cfa }}^{2}$

It can be seen that any attempt to study firn and ice diffusion by means of ice core data obtained with an on-line method similar to the one we present here, requires a good assesment of the diffusive properties of the experimental system. The latter is possible if one is able to estimate the variance of the smoothing filter $\mathcal{G}_{\text {cfa }}$ expressed by the variance $\sigma_{\text {cfa }}^{2}$ (hereafter diffusion length). One way to approach this problem is to measure the response of the system to a step function. Ideally, in the case of zero diffusion, a switch between two 


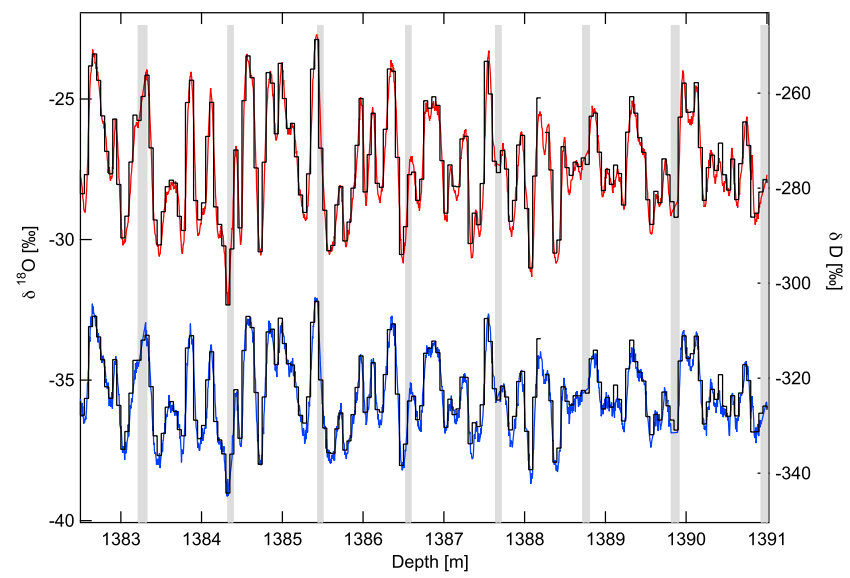

Fig. 6. Comparison CRDS-CFA with $5 \mathrm{~cm}$ discrete samples for $\delta \mathrm{D}$ (top) and $\delta^{18} \mathrm{O}$ (bottom). Bars indicate the position and width of sections with missing/removed data.

isotopic levels would be described by a scaled and shifted version of the the Heaviside unit step function as:

$\delta_{\mathrm{H}}(z)= \begin{cases}C_{2} & z<0 \\ C_{1} H(z)+C_{2} & z \geq 0\end{cases}$

where the isotopic shift takes place at $z=0, H(z)$ is the Heaviside unit step function and $C_{1}$ and $C_{2}$ refer to the amplitude and base line level of the isotopic step. Convolution of the signal of Eq. (5) with $\mathcal{G}_{\text {cfa }}$ and subsequent calculation of the derivative yields,

$\frac{d \delta_{\mathrm{m}}}{d z}=\frac{d \delta_{\mathrm{H}}}{d z} * \mathcal{G}_{\mathrm{cfa}}=C_{1} \frac{d H}{d t} * \mathcal{G}_{\mathrm{cfa}}=C_{1} \delta_{\text {Dirac }} * \mathcal{G}_{\mathrm{cfa}}$

Thus the derivative of the measured signal, properly normalized, equals the impulse respone of the system. Applying the Fourier transform, denoted by the overhead hat symbol, in Eq. (6), and by using the convolution theorem, we deduce the transfer function $\hat{\mathcal{G}}_{\text {cfa }}$ of the system:

$\frac{\widehat{d \delta_{\mathrm{m}}}}{d z}=C_{1} \hat{\delta}_{\text {Dirac }} \cdot \hat{\mathcal{G}}_{\mathrm{cfa}}=C_{1} \cdot \hat{\mathcal{G}}_{\mathrm{cfa}}$

In the case of the system presented here, an isotopic transition can be observed when the main CFA valve (V1 in Fig. 1) switches between $\mathrm{mQ}$ water and sample at the beginning and the end of each CFA run as shown in Fig. 4. By using these transitions we are able to construct isotopic steps and estimate the impulse response of the system. Such an isotopic step is illustrated in Fig. 7a. We fit the data of Fig. 7a with a scaled version of the cumulative distribution function of a normal distribution described as

$\delta_{\text {model }}(z)=\frac{C_{1}^{\prime}}{2}\left[1+\operatorname{erf}\left(\frac{z-z_{0}}{\sigma_{\text {step }} \sqrt{2}}\right)\right]+C_{2}^{\prime}$

The values of $C_{1}^{\prime}, C_{2}^{\prime}, z_{0}$ and $\sigma_{\text {step }}$ are estimated by means of a least square optimization and used accordingly to normalize the length scale and the isotopic values of the step.
A nominal melt rate of $3.2 \mathrm{~cm} \mathrm{~min}^{-1}$ is used for all the calculations presented here. We focus our analysis on the $\delta \mathrm{D}$ signal. The same approach can be followed for $\delta^{18} \mathrm{O}$. In Fig. $7 \mathrm{~b}$ we present the calculated impulse response of the system. The latter can be well approximated by a Gaussian type filter described as:

$\mathcal{G}_{\mathrm{cfa}}(z)=\frac{1}{\sigma_{\mathrm{cfa}} \sqrt{2 \pi}} e^{-\frac{z^{2}}{2 \sigma_{\mathrm{cfa}}^{2}}}$

The diffusion length term $\sigma_{\text {cfa }}$ is equal to $13.4 \pm 0.17 \mathrm{~mm}$ $(1 \sigma)$ as calculated with the least squares optimization. The transfer function for this filter will be given by its Fourier transform, which is itself a Gaussian and is equal to (Abramowitz and Stegun, 1964):

$\mathfrak{F}\left[\mathcal{G}_{\mathrm{cfa}}(z)\right]=\hat{\mathcal{G}}_{\mathrm{cfa}}=\frac{1}{2 \pi} \int_{-\infty}^{\infty} \frac{1}{\sigma_{\mathrm{cfa}} \sqrt{2 \pi}} e^{-\frac{z^{2}}{2 \sigma_{\mathrm{cfa}}^{2}}} e^{-i k z} d k=e^{\frac{-k^{2} \sigma_{\mathrm{cfa}}^{2}}{2}}$

where $k=\frac{2 \pi}{\lambda}$ and $\lambda$ is the wavelength ${ }^{4}$ of a harmonic of the isotopic signal. Harmonics with an initial amplitude $A_{0}$ and wavenumber $k$ will be attenuated to a final amplitude equal to:

$A=A_{0} e^{\frac{-k^{2} \sigma_{\mathrm{cfa}}^{2}}{2}}$

An estimate of the transfer function based on the data and the cumulative distribution model is presented in Fig. 8 (blue and pink curve, respectively). As seen in this plot, cycles with wavelengths longer than $25 \mathrm{~cm}$ experience negligible attenuation, whereas cycles with a wavelength of $7 \mathrm{~cm}$ are attenuated by $\approx 50 \%$.

The step response approach has been followed in the past for on-line chemistry data. In some studies such as Sigg et al. (1994) and Rasmussen et al. (2005), the resolution of the experimental system was assessed via the estimation of the transfer function. In other studies (Röthlisberger et al., 2000; Kaufmann et al., 2008), the characteristic time in which a step reaches a certain level (typically $1 / e$ ) with respect to its final value, is used as a measure of the obtained resolution of the system. A common weakness of this approach as applied in the current, as well as previous studies, is that it is based on the analysis of a step that is introduced in the analytical system by switching a valve that is typically situated downstream of the melting and the debubbling system. Consequently, the impact of these last two elements on the smoothing of the obtained signals is neglected. In this study, this is the valve V1 in Fig. 1.

To overcome this problem we will present here an alternative way, based on the comparison of the spectral properties of the on-line CFA data and the off-line discrete data in $5 \mathrm{~cm}$ sampling resolution, presented in Sect. 3.2. In this approach

\footnotetext{
${ }^{4}$ Here the term wavelength refers to the isotopic signal in the ice and should not be confused with the wavelength of the light emitted by the laser diode of the spectrometer.
} 

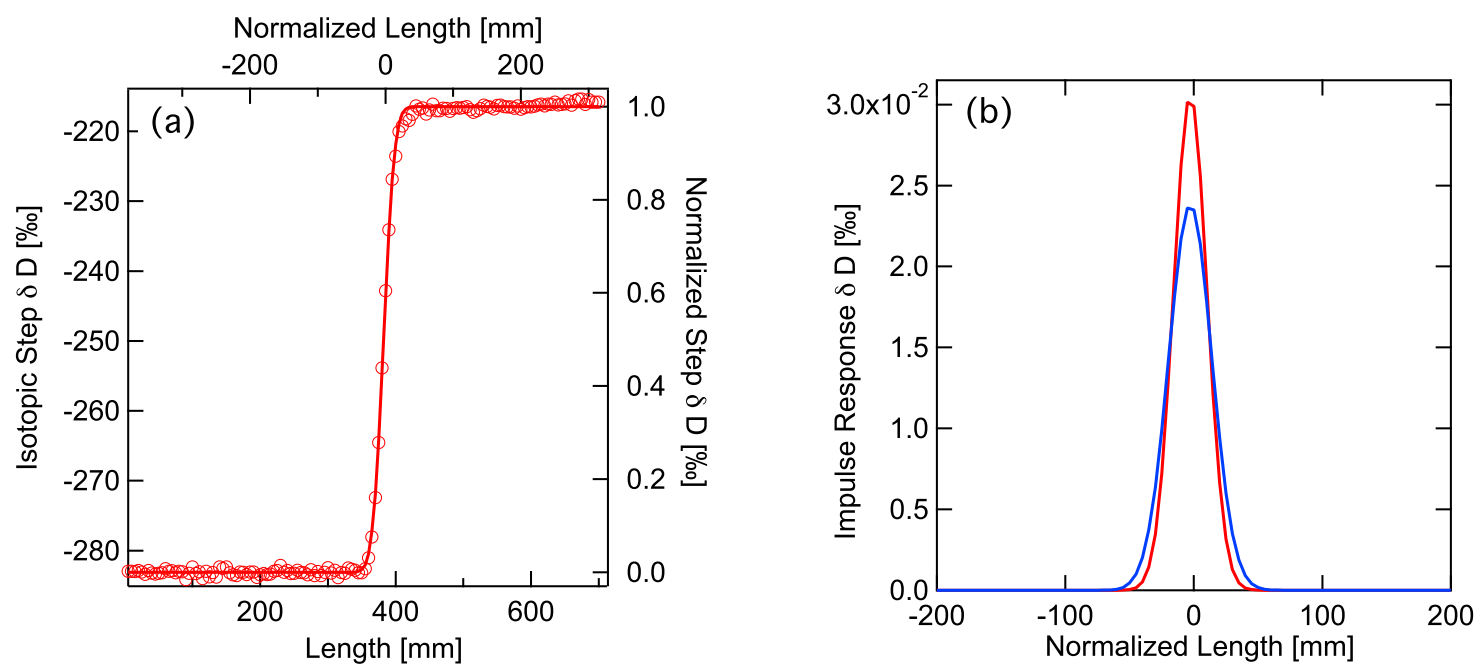

Fig. 7. (a) Isotopic $\delta \mathrm{D}$ step. The length scale is normalized so normalized length $=0$ when the normalized $\delta \mathrm{D}$ value equals $0.5 \%$. (b) Impulse Response of the system for $\delta \mathrm{D}$ based on the step response (red) and the spectral analysis (blue) with $\sigma_{\mathrm{cfa}}=13.4$ and $16.4 \mathrm{~mm}$, respectively.
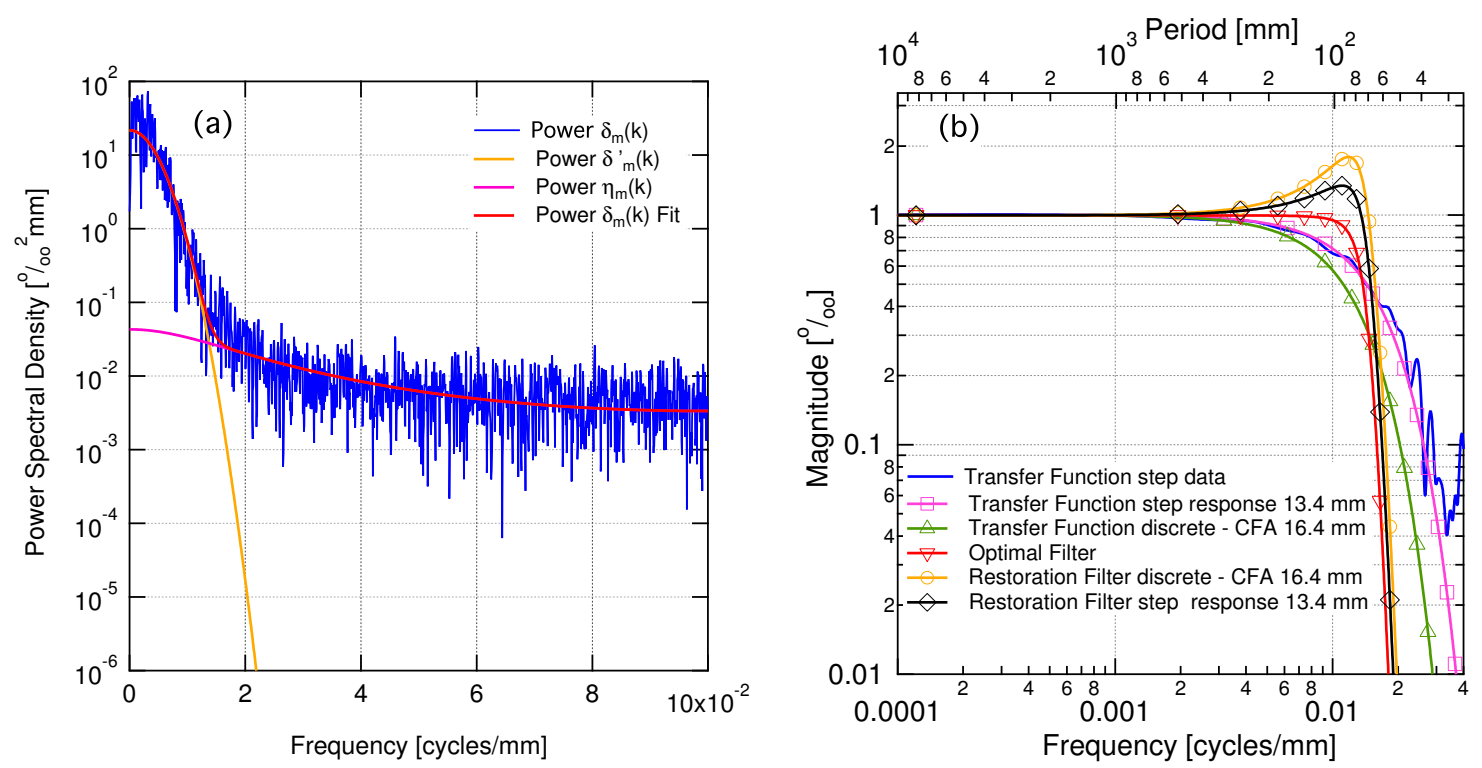

Fig. 8. (a) Power spectral density of $\delta$ D. (b) Transfer function calculated based on the step response with $\sigma_{\text {cfa }}=13.4 \mathrm{~mm}$ (pink - squares) and the comparison between discrete and CFA analysis with $\sigma_{\mathrm{cfa}}=16.4 \mathrm{~mm}$ (green - triangles). Restoration filters built considering the two different transfer functions are illustrated with orange circles $\left(\sigma_{\mathrm{cfa}}=16.4 \mathrm{~mm}\right)$ and black diamonds $\left(\sigma_{\mathrm{cfa}}=13.4 \mathrm{~mm}\right)$.

the diffusion length of the total smothing filter for the off-line discrete analysis will be:

$\sigma_{\text {off }}^{2}=\sigma_{\text {firn }}^{2}+\sigma_{5 \mathrm{~cm}}^{2}$

where $\sigma_{5 \mathrm{~cm}}^{2}$ is the diffusion length of the smoothing imposed by the sample cutting scheme at a $5 \mathrm{~cm}$ resolution. If one averages the on-line CFA data at a $5 \mathrm{~cm}$ resolution by means of a running mean filter, the diffusion length of the total smoothing filter for the on-line CFA measurements averaged on a $5 \mathrm{~cm}$ resolution will be: $\sigma_{\mathrm{on}}^{2}=\sigma_{\mathrm{firn}}^{2}+\sigma_{5 \mathrm{~cm}}^{2}+\sigma_{\mathrm{cfa}}^{2}$

From Eqs. (12) and (13) we get:

$\sigma_{\text {cfa }}^{2}=\sigma_{\text {on }}^{2}-\sigma_{\text {off }}^{2}$

As a result, the term $\sigma_{\mathrm{on}}^{2}-\sigma_{\mathrm{off}}^{2}$ is directly related to the diffusion length of the smoothing filter of the whole CFA-water isotope system including the melting and debubbling sections. Based on Eq. (11), the power spectral density of the signals will be: 


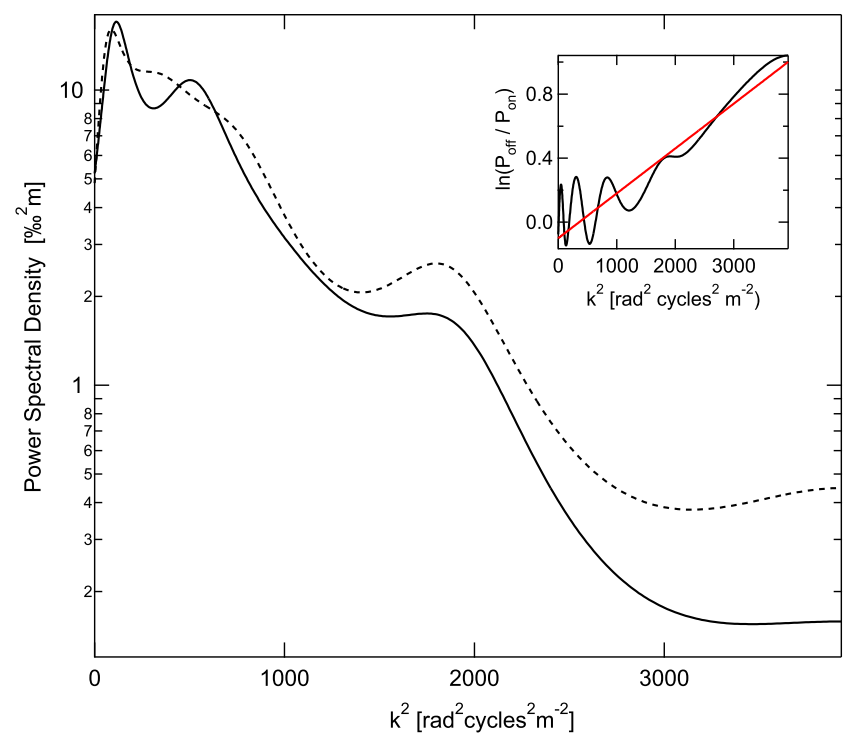

Fig. 9. Calculation of the diffusion length for the transfer function of the CFA system. The dashed and solid lines represent, respectively the power spectral density of the offline discrete data and the CFA data averaged on a $5 \mathrm{~cm}$ resolution.

$P=P_{0} e^{-k^{2} \sigma^{2}}$

where $\sigma^{2}$ refers in this case to $\sigma_{\text {on }}^{2}$ or $\sigma_{\text {off }}^{2}$. Combining the power spectral densities of the on-line and off-line time series we finally get:

$\ln \left(\frac{P_{\text {off }}}{P_{\text {on }}}\right)=\ln \left(\frac{P_{0 \text { off }}}{P_{0 \text { on }}}\right)+\sigma_{\text {cfa }}^{2} k^{2}$

Hence, the logarithm of the ratio $P_{\mathrm{off}} / P_{\mathrm{on}}$ is linearly related to $k^{2}$ with a slope equal to $\sigma_{\text {cfa }}^{2}$. In Fig. 9 we perform this analysis for $\delta \mathrm{D}$ and by applying a linear fit we calculate the $\sigma_{\mathrm{cfa}}[D]$ to be equal to $16.4 \pm 2.4 \mathrm{~mm}$. In a similar manner $\sigma_{\mathrm{cfa}}[O 18]$ is found to be equal to $16.8 \pm 2.3 \mathrm{~mm}$.

The higher value calculated with the spectral method points to the additional diffusion of the sample at the melter and debubbler system that could not be considered in the analysis based on the step response. The impulse response of the system based on the updated value of $\sigma_{\text {cfa }}^{2}$ is presented in Fig. 6.

\subsection{Optimal filtering}

In the ideal case of a noise-free measured signal $\delta_{\mathrm{m}}^{\prime}(z)$ and provided that the transfer function $\hat{\mathcal{G}}_{\text {cfa }}$ is known, one can reconstruct the initial isotopic signal $\delta_{\mathrm{i}}(z)$ from Eq. (3) as:

$\delta_{\mathrm{i}}(z)=\frac{1}{2 \pi} \int_{-\infty}^{\infty} \frac{\hat{\delta}_{\mathrm{m}}^{\prime}(k)}{\hat{\mathcal{G}}(k)} e^{i k z} d k$

where the integral operation denotes the inverse Fourier transform and $k=\frac{2 \pi}{\lambda}$ with $\lambda$ being the wavelength of the isotopic signals. In the presence of measurement noise $\eta(z)$, this approach will fail due to excess amplification of the high frequency noise channels in the spectrum of the signal.

Hereby we use the Wiener approach in deconvoluting the acquired isotopic signals for the diffusion that takes place during the measurement. Considering a measured isotopic signal

$\delta_{\mathrm{m}}(z)=\delta_{\mathrm{m}}^{\prime}(z)+\eta(z)$

an optimal filter $\varphi(z)$ can be constructed that when used at the deconvolution step, it results in an estimate of the initial isotopic signal described as:

$\tilde{\delta}_{i}(z)=\frac{1}{2 \pi} \int_{-\infty}^{\infty} \frac{\hat{\delta}_{\mathrm{m}}(k)}{\hat{\mathcal{G}}(k)} \hat{\varphi}(k) e^{i k z} d k$

Assuming that $\delta_{\mathrm{m}}^{\prime}(z)$ and $\eta(z)$ are uncorrelated signals, the optimal filter is given by:

$\hat{\varphi}(k)=\frac{\left|\hat{\delta}_{\mathrm{m}}^{\prime}(k)\right|^{2}}{\left|\hat{\delta}_{\mathrm{m}}^{\prime}(k)\right|^{2}+|\hat{\eta}(k)|^{2}}$

(Wiener, 1949); where $\left|\hat{\delta}_{\mathrm{m}}^{\prime}(k)\right|^{2}$ and $|\hat{\eta}(k)|^{2}$ are the power spectral densities of the signals $\delta_{\mathrm{m}}^{\prime}(z)$ and $\eta(z)$.

In the same fashion as in the previous section we assume that the spectrum of the noise free measured signal $\left|\hat{\delta}_{\mathrm{m}}^{\prime}(k)\right|^{2}$, is described by Eq. (15) where $\sigma^{2}=\sigma_{\text {tot }}^{2}$. Regarding the noise, we assume red noise described by an AR1 process. The spectrum of the noise signal will then be described by (Kay and Marple, 1981):

$|\hat{\eta}(k)|^{2}=\frac{\sigma_{\eta}^{2} \Delta z}{\left|1+a_{1} \exp (-i k \Delta z)\right|^{2}}$

where $\sigma_{\eta}^{2}$ is the variance of the noise and $a_{1}$ is the coefficient of the AR 1 process. We vary the parameters $\sigma_{\text {tot }}^{2}, P_{0}$, $\sigma_{\eta}^{2}$ and $a_{1}$ so that the sum $\left|\hat{\delta}_{\mathrm{m}}(k)\right|^{2}=\left|\hat{\delta}_{\mathrm{m}}^{\prime}(k)\right|^{2}+|\hat{\eta}(k)|^{2}$ fits the spectrum of the measured signal. The set of parameters that results in the optimum fit is used to calculate the optimal filter.

The constructed filters together with the transfer functions that were calculated based on the two different techniques outlined in Sect. 3.4 are illustrated in Fig. 8. One can observe how the restoration filters work by amplifying cycles with wavelengths as low as $7 \mathrm{~mm}$. Beyond that point, the shape of the optimal filter attenuates cycles with higher frequency, which lie in the area of noise. An example of deconvoluted $\delta \mathrm{D}$ data section is given in Fig. 10. It can be seen that the effect of the optimal filtering results in both the amplification of the signals that are damped due to the instrumental diffusion, as well as in the filtering of the measurement noise.

\subsection{Information on deuterium excess}

Combining $\delta^{18} \mathrm{O}$ and $\delta \mathrm{D}$ gives the deuterium excess as $\mathrm{D}_{\mathrm{xs}}=\delta \mathrm{D}-8 \delta^{18} \mathrm{O}$ (Craig et al., 1963; Mook, 2000). The 


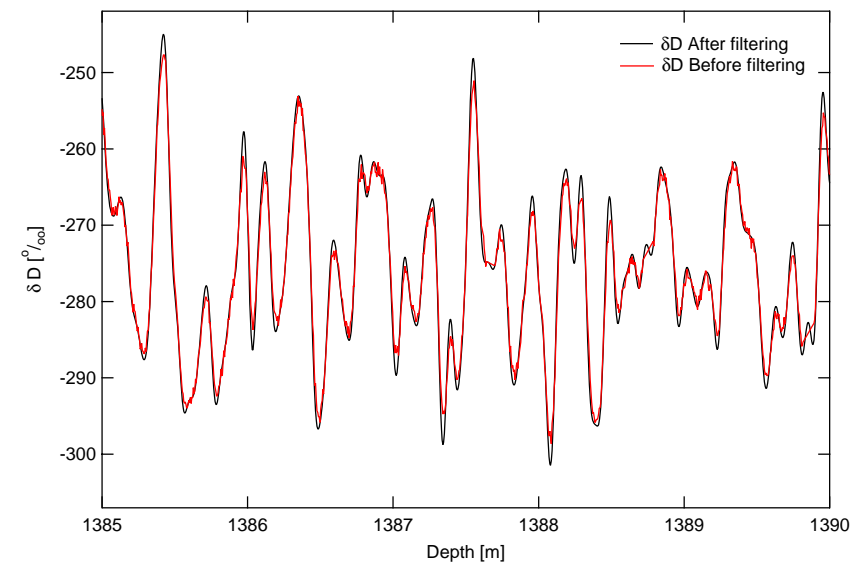

Fig. 10. $\delta \mathrm{D}$ signal before and after optimal filtering.

noise level of the $D_{x s}$ signal can be calculated by the estimated noise levels of $\delta^{18} \mathrm{O}$ and $\delta \mathrm{D}$ as:

$\sigma_{\mathrm{D}_{\mathrm{xs}}}=\sqrt{\sigma_{\mathrm{D}}^{2}+64 \cdot \sigma_{18}^{2}}=0.48 \%$ o

As seen in Fig. 11, the $D_{\mathrm{xs}}$ signal presents a low signal to noise ratio. In this case, the technique of optimal filtering can effectively attenuate unwanted high frequency noise components, thus reveiling a "clean" $D_{x s}$ signal.

The latter offers the possibility for the study of abrubt transitions as they have previously been investigated in $\delta^{18} \mathrm{O}, \delta \mathrm{D}$ and $\mathrm{D}_{\mathrm{xs}}$ time series from discrete high resolution samples (Steffensen et al., 2008). The on-line fashion in which these measurements are performed has the potential to yield not only higher temporal resolution but also better statistics for those climatic transitions.

\section{Summary and conclusions}

We have succesfully demonstrated the possibility for on-line water isotopic analysis on a continuously melted ice core sample. We used an infrared laser spectrometer in a cavity ring down configuration in combination with a continuous flow melter system. A custom made continuous stream flash evaporator served as the sample preparation unit, interfacing the laser spectrometer to the melter system.

Local water standards have been used in order to calibrate the measurements to the VSMOW scale. Additionally, dependencies related to the sample size in the optical cavity have been accounted for. The melting procedure is recorded by an optical encoder that provides the necessary information for assigning a depth scale to the isotope measurements. We verified the validity of the applied calibrations and the calculated depth scale by comparing the CFA measurements with measurements performed on discrete samples in $5 \mathrm{~cm}$ resolution.

By means of spectral methods we provide an estimate of the noise level of the measurements. The combined uncertainty of the measurement is estimated at $\approx 0.06,0.2$, and

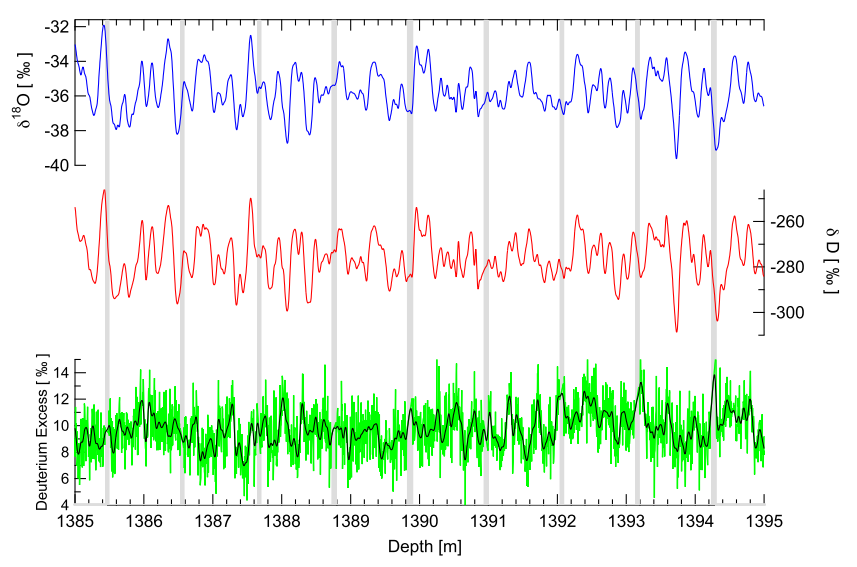

Fig. 11. $\delta^{18} \mathrm{O}, \delta \mathrm{D}$ and $\mathrm{D}_{\mathrm{xs}}$ signals after the optimal filtering. For the $D_{\mathrm{xs}}$ we present the signal before (light green) and after (black) the filtering. Gray bars indicate the position and width of sections with missing/removed data.

$0.5 \%$ for $\delta^{18} \mathrm{O}, \delta \mathrm{D}$ and $\mathrm{D}_{\mathrm{xs}}$, respectively. This performance is comparable to, or better than the performance typically achieved with conventional IRMS systems in a discrete mode.

Based on the isotopic step at the beginning of each CFA run, the impulse response, as well as the transfer function of the system can be estimated. We show how this method does not take into account the whole CFA system, thus underestimating the sample diffusion that takes place from the melter until the optical cavity of the spectrometer. We proposed a different method that considers the power spectrum of the CFA data in combination with the spectrum of a data set over the same depth interval measured in a discrete offline fashion. The use of the optimal filtering deconvolution technique, provides a way to deconvolute the measured isotopic profiles for apparent sample dispersion effects.

The combination of infrared spectroscopy on gaseuous samples with continuous flow melter systems provides new possibilities for ice core science. The non destructive, continuous, and on-line technique offers the possibility for analysis of multiple species on the same sample in high resolution and precision and can potentially be performed in the eld.

Acknowledgements. We would like to thank Dorthe Dahl Jensen for supporting our research. Numerous drillers, core processors and general field assistants have contributed to the NEEM ice core drilling project with weeks of intensive field work. Withought this collective effort, the measurements we present here would not be possible. Bruce Vaughn and James White have contributed to this project with valuable comments and ideas. This project was partly funded by the Marie Curie Research Training Network for Ice Sheet and Climate Evolution (MRTN-CT-2006-036127).

Edited by: P. Werle 


\section{References}

Abramowitz, M. and Stegun, I. A.: Handbook of Mathematical Functions with Formulas, Graphs, and Mathematical Tables, Dover, New York, 1964.

Accoe, F., Berglund, M., Geypens, B., and Taylor, P.: Methods to reduce interference effects in thermal conversion elemental analyzer/continuous flow isotope ratio mass spectrometry $\delta^{18} \mathrm{O}$ measurements of nitrogen-containing compounds, Rapid Commun. Mass Sp., 22, 2280-2286, 2008.

Andersen, N.: Calculation of filter coefficients for maximum entropy spectral analysis, Geophysics, 39, 69-72, 1974.

Begley, I. S. and Scrimgeour, C. M.: High-precision $\delta^{2} \mathrm{H}$ and $\delta^{18} \mathrm{O}$ measurement for water and volatile organic compounds by continuous-flow pyrolysis isotope ratio mass spectrometry, Anal. Chem., 69, 1530-1535, 1997.

Bigeleisen, J., Perlman, M. L., and Prosser, H. C.: Conversion of hydrogenic materials to hydrogen for isotopic analysis, Anal. Chem., 24, 1356-1357, 1952.

Brand, W. A., Geilmann, H., Crosson, E. R., and Rella, C. W.: Cavity ring-down spectroscopy versus high-temperature conversion isotope ratio mass spectrometry; a case study on $\delta^{2} \mathrm{H}$ and $\delta^{18} \mathrm{O}$ of pure water samples and alcohol/water mixtures, Rapid Commun. Mass Sp., 23, 1879-1884, doi:10.1002/rcm.4083, 2009.

Burg, J. P.: Maximum Entropy Spectral Analysis, Ph.D. thesis, Stanford University, 1975.

Craig, H., Gordon, L. I., and Horibe, Y.: Isotopic exchange effects in evaporation of water low-temperature experimental results, J. Geophys. Res., 68, 5079-5087, 1963.

Crosson, E. R.: A cavity ring-down analyzer for measuring atmospheric levels of methane, carbon dioxide, and water vapor, Appl. Phys. B-Lasers O., 92, 403-408, 2008.

Cuffey, K. M. and Vimeux, F.: Covariation of carbon dioxide and temperature from the Vostok ice core after deuterium-excess correction, Nature, 412, 523-527, 2001.

Dansgaard, W.: Stable isotopes in precipitation, Tellus, 16, 436468, 1964.

Epstein, S. and Mayeda, T.: Variations of ${ }^{18} \mathrm{O}$ content of waters from natural sources, Geochim. Cosmochim. Ac., 4, 213-224, 1953.

Gehre, M., Hoefling, R., Kowski, P. and Strauch, G.: Sample preparation device for quantitative hydrogen isotope analysis using chromium metal, Anal. Chem., 68, 4414-4417, 1996.

Gkinis, V., Popp, T. J., Johnsen, S. J., and Blunier, T.: A continuous stream flash evaporator for the calibration of an IR cavity ring down spectrometer for isotopic analysis of water, Isot. Environ. Health S., 46, 1-13, 2010.

Gupta, P., Noone, D., Galewsky, J., Sweeney, C., and Vaughn, B. H.: Demonstration of high-precision continuous measurements of water vapor isotopologues in laboratory and remote field deployments using wavelength-scanned cavity ring-down spectroscopy (WS-CRDS) technology, Rapid Commun. Mass Sp., 23, 25342542, 2009.

Huber, C. and Leuenberger, M.: Fast high-precision on-line determination of hydrogen isotope ratios of water or ice by continuous-flow isotope ratio mass spectrometry, Rapid Commun. Mass Sp., 17, 1319-1325, 2003.

Johnsen, S.: Stable isotope homogenization of polar firn and ice, Isotopes and Impurities in Snow and Ice, 210-219, 1977.

Johnsen, S. J., Dansgaard, W., and White, J. W. C.: The origin of
Arctic precipitation under present and glacial conditions, Tellus, 41B, 452-468, 1989.

Johnsen, S. J., Clausen, H., Dansgaard, W., Fuhrer, K., Gundestrup, N., Hammer, C., Iversen, P., Jouzel, J., Stauffer, B., and Steffensen, J.: Irregular glacial interstadials recorded in a new Greenland ice core, Nature, 359, 311-313, 1992.

Johnsen, S. J., Clausen, H. B., Cuffey, K. M., Hoffmann, G., Schwander, J., and Creyts, T.: Diffusion of stable isotopes in polar firn and ice, The isotope effect in firn diffusion, in: Physics of Ice Core Records, edited by: Hondoh, T., Hokkaido University Press, Sapporo, 121-140, 2000.

Johnsen, S. J., Dahl Jensen, D., Gundestrup, N., Steffensen, J. P., Clausen, H. B., Miller, H., Masson-Delmotte, V., Sveinbjörnsdóttir, A. E., and White, J. W. C.: Oxygen isotope and palaeotemperature records from six Greenland ice-core stations: Camp Century, Dye-3, GRIP, GISP2, Renland and NorthGRIP, J. Quaternary Sci., 16, 299-307, 2001.

Jouzel, J. and Merlivat, L.: Deuterium and oxygen 18 in precipitation: modeling of the isotopic effects during snow formation, J. Geophys. Res.-Atmos., 89, 11749-11759, 1984.

Jouzel, J., Alley, R. B., Cuffey, K. M., Dansgaard, W., Grootes, P., Hoffmann, G., Johnsen, S. J., Koster, R. D., Peel, D., Shuman, C. A., Stievenard, M., Stuiver, M., and White, J. W. C.: Validity of the temperature reconstruction from water isotopes in ice cores, J. Geophys. Res.-Oceans, 102, 26471-26487, 1997.

Kaufmann, P. R., Federer, U., Hutterli, M. A., Bigler, M., Schüpbach, S., Ruth, U., Schmitt, J., and Stocker, T. F.: An improved continuous flow analysis system for high-resolution field measurements on ice cores, Environ. Sci. Technol., 42, 80448050, 2008.

Kavanaugh, J. L. and Cuffey, K. M.: Generalized view of sourceregion effects on $\delta \mathrm{D}$ and deuterium excess of ice-sheet precipitation, Ann. Glaciol., 35, 111-117, 2002.

Kay, S. M. and Marple, S. L.: Spectrum analysis - a modern perspective, P. IEEE, 69, 1380-1419, 1981.

Kerstel, E. R. T.: Handbook of Stable Isotope Analytical Techniques, Vol. 1, Elsevier B. V., Amsterdam, 2004.

Kerstel, E. R. T., van Trigt, R., Dam, N., Reuss, J., and Meijer, H. A. J.: Simultaneous determination of the ${ }^{2} \mathrm{H} /{ }^{1} \mathrm{H},{ }^{17} \mathrm{O} /{ }^{16} \mathrm{O}$ and ${ }^{18} \mathrm{O} /{ }^{16} \mathrm{O}$ isotope abundance ratios in water by means of laser spectrometry, Anal. Chem., 71, 5297-5303, 1999.

Lis, G., Wassenaar, L. I., and Hendry, M. J.: High-precision laser spectroscopy $\mathrm{D} / \mathrm{H}$ and $\mathrm{O}-18 / \mathrm{O}-16$ measurements of microliter natural water samples, Anal. Chem., 80, 287-293, 2008.

Mook, W.: Environmental Isotopes in the Hydrological Cycle: Principles and Applications, Vol. I, International Atomic Energy Agency, 2000.

NGRIP members: High-resolution record of Northern Hemisphere climate extending into the last interglacial period, Nature, 431, 147-151, 2004.

Rasmussen, S. O., Andersen, K. K., Johnsen, S. J., Bigler, M., and McCormack, T.: Deconvolution-based resolution enhancement of chemical ice core records obtained by continuous flow analysis, J. Geophys. Res.-Atmos., 110, D17304, doi:10.1029/2004JD005717, 2005.

Rasmussen, S. O., Andersen, K. K., Svensson, A. M., Steffensen, J. P., Vinther, B. M., Clausen, H. B., SiggaardAndersen, M. L., Johnsen, S. J., Larsen, L. B., Dahl-Jensen, D., Bigler, M., Röthlisberger, R., Fischer, H., Goto-Azuma, K., 
Hansson, M. E., and Ruth, U.: A new Greenland ice core chronology for the last glacial termination, J. Geophys. Res.Atmos., 111, D06102, doi:10.1029/2005JD006079, 2006.

Röthlisberger, R., Bigler, M., Hutterli, M., Sommer, S., Stauffer, B., Junghans, H. G., and Wagenbach, D.: Technique for continuous high-resolution analysis of trace substances in firn and ice cores, Environ. Sci. Technol., 34, 338-342, 2000.

Schüpbach, S., Federer, U., Kaufmann, P. R., Hutterli, M. A., Buiron, D., Blunier, T., Fischer, H., and Stocker, T. F.: A new method for high-resolution methane measurements on polar ice cores using continuous flow analysis, Environ. Sci. Technol., 43, 5371-5376, 2009.

Sigg, A., Führer, K., Anklin, M., Staffelbach, T., and Zurmuhle, D.: A continuous analysis technique for trace species in ice cores, Environ. Sci. Technol., 28, 204-209, 1994.
Steffensen, J., Andersen, K., Bigler, M., Clausen, H., DahlJensen, D., Fischer, H., Goto-Azuma, K., Hansson, M., Johnsen, S., Jouzel, J., Masson-Delmotte, V., Popp, T. J., Rasmussen, S. O., Röthlisberger, R., Ruth, U., Stauffer, B., SiggaardAndersen, M. L., Sveinbjörnsdóttir, A., Svensson, A., and White, J. W. C.: High-resolution Greenland ice core data show abrupt climate change happens in few years, Science, 321, 680 6842008.

Vaughn, B. H., White, J. W. C., Delmotte, M., Trolier, M., Cattani, O., and Stievenard, M.: An automated system for hydrogen isotope analysis of water, Chem. Geol., 152, 309-319, 1998.

Whillans, I. and Grootes, P.: Isotopic diffusion in cold snow and firn, J. Geophys. Res., 90, 3910-3918, 1985.

Wiener, N.: Time Series, The MIT Press, Cambridge, Massachussetts, 1949. 